\title{
Terrestrial and Extraterrestrial Altruism
}

\author{
Holmes Rolston III
}

\begin{abstract}
How Earthbound are values and ethics? We humans enjoy a surprising transcendence of localized body and place. We are always situated somewhere, but it does not follow that all our knowledge is situational. True, science is a human enterprise. True, ethics is a human activity - even biologically-based. But can we expect to share some of our science and ethics with extraterrestrials? Perhaps in the search for extraterrestrial intelligence, the question to ask is not about the value of pi, or the atomic number of carbon. A more revealing test might be to ask whether one should tell the truth, keep promises, or be just. The Golden Rule may be as universally true as is the theory of relativity.
\end{abstract}

Keywords Altruism • Ethics $•$ Extraterrestrials $\bullet$ Golden Rule $\bullet$ Promises $\bullet$ Justice $\bullet$ Truth-telling

\section{Introduction}

We humans live in place, locally on landscapes and globally on this planet. We have powers of displacement too, of getting out of our places and taking up, whether empathetically or objectively, the situations of others, other humans, sometimes others than humans. There is a human genius for transcending location. Critics will at once object that whatever knowledge we gain has to "come through" at our native range. Have I forgotten that philosophers have perennially found themselves in an epistemic prison? There is no human knowing that is not looking out from where we are, using our senses and our brains, from an anthropocentric perspective.

H. Rolston III $(\square)$

Department of Philosophy, Colorado State University, Campus Delivery 1781, Fort Collins, CO 80523-1781, USA

e-mail: rolston@lamar.colostate.edu

D. A. Vakoch (ed.), Extraterrestrial Altruism, The Frontiers Collection, 
That seems uncontroversial, but does this imply that we can see and know no others as they are in themselves, nothing non-anthropocentric, nothing true apart from our looking, nothing external? Yes - so at least runs the currently fashionable answer. Knowledge is relative to our location, our embodiment, our size, our terrestrial habitat. We do not have a "view from nowhere," no "God's eye view." Everybody has a "body," everybody has a "standpoint," a "viewpoint." We are incarnate, in the flesh, and our particular form of embodiment poses "epistemological" problems - for which, in Western philosophy, a classic metaphor is Plato's men in the cave, or, in the East, the blind men and the elephant. In contemporary idiom, postmodernists insist that all our knowledge is "socially constructed." Knowledge is relative to our worldviews; realism, even a critical realism, is thought to be quite naive. Our knowledge wears a human face.

True, we never experience a dis-embodied, un-placed, or other-worldly mind. But we do gain views that look out from our bodies and places and see what is out-of-my-body, out-of-my-place. Had we been microbes or octopuses, our native ranges of perception and conception would be different. But we humans also enjoy a surprising transcendence of localized body and place. We are always situated somewhere, but it does not follow that all our knowledge is situational.

My progression of argument here first explores this search for objectivity and transcendence in science. Then we press a parallel question in ethics, pushing toward universality. If you prefer another way of phrasing this, avoiding such disfavored terms as "objective" and "universal," we are asking how "inclusive" and "comprehensive" can science and ethics be? This question is relevant even if our interests stay Earthbound. The question will further figure into the search for intelligent life elsewhere. Can we expect to share some of our science and ethics with extraterrestrials?

\section{Terrestrial and Extraterrestrial Science}

Once upon a time natural history produced humans, and some of these humans have become scientists. Some of these scientists have given us an account of natural history, out of which they (and all other living beings) evolved. This science is done with native endowments, brains, eyes, hands; this science has built up over centuries of cumulative transmissible cultures. We are not born scientists; we are educated to become chemists or biologists. Such science is a dominant fact of modern culture.

The natural sciences certainly seem to open up a world that is objectively there; they contact, catch, describe it more and less accurately: evolutionary history with its trilobites and dinosaurs, ecology with its phenotypes, genotypes, and trophic pyramids. True, the scientists have a network of theories they have constructed, but this network hits up against a hard world of experience. Some things have been "found" out. The human mind sometimes seems to be able to reach truths about realms that it does not inhabit, extrapolating and reasoning from the realms it does. 
We learn this even at native ranges in biology. Humans reach outside their own sector to study warblers, viruses, and dinosaurs. We learn much that underlies our native range of experience but is not self-evident: life is carbon-based and photosynthesis is the primary biochemistry for capturing solar energy.

Humans become still more universal in their physics and inorganic chemistry, learning about the microworlds of elementary waves and particles, about the astronomical worlds of outer space. Martians too, when doing chemistry, will have to figure the conservation of charge, energy, and mass, and balance their equations. Science employs biologically evolved perceptual and conceptual faculties, it is a social construct; but, for all that, it sometimes flowers to discover objective truths - such as relativity theory or the atomic table, which are true all over our universe.

How far can we see out of our native range? Microscopes and telescopes come immediately to mind, making visible the microbes and galaxies. Today neither the microscopes nor telescopes have to be light-based. Such instrumentation expands to Geiger counters, mass spectrometers, and on and on. Alone among the species on Earth, all embodied, Homo sapiens is cognitively remarkable. With our instrumented intelligences and constructed theories, we now know of phenomena at structural levels from quarks to quasars. We measure distances from picometers to the extent of the visible universe in light years, across 40 orders of magnitude. We measure the strengths of the four major binding forces in nature (gravity, electromagnetism, the strong and weak nuclear forces), again across 40 orders of magnitude. We measure time at ranges across 30 orders of magnitude, from picoseconds to the billions-of-years age of the universe. Nature gave scientists their mind-sponsoring brains; nature gave scientists their hands. Nature did not give scientists radiotelescopes with which to "see" pulsars, or relativity theory with which to compute time dilation. These come from human genius.

These extremes are quite beyond our embodied experience. No one experiences a light year or a picosecond. But they are not beyond our comprehension entirely, else we could not use such concepts so effectively in science. The instrumentation is a construction (microscopes and mathematics), a "social construct," if you must. Certainly the data on these instruments comes through at native range, as we read the meters or computer output. But precisely this construction enables us dramatically to extend our native ranges of perception. The construction distances us from our embodiment.

No one has an everyday "picture" of a quark or a pulsar. So if one wants to lampoon the perfect "mirror" image at these extremes of range, this is easy to do. But we have good theory why nothing can be "seen" at such ranges in ordinary senses of "see," which requires light in the wavelength range of $400-700 \mathrm{~nm}$, with quarks and pulsars far outside that range. We can ask whether a molecule is too small to be colored, or whether an electron, in its superposition states, is so radically different as to have no position, no "place" in the native range sense, but only a probabilistic location.

"Absolute" is a forbidding word; it seems too metaphysically transcendent. "Universal," also a term currently disliked by philosophers, is still welcomed by 
scientists; the term is at least this-worldly, oriented toward "our" universe. Scientists have what Michael Polanyi $(1962,65)$ called "universal intent"; they hope for theories true at all times and places, true for all peoples everywhere. If this is true in science, we can also ask whether the human mind can reach ethical principles that may transcend our somatic embodiment. It might be that in the search for extraterrestrial intelligence, the question to ask is about the value of $p i$, or the atomic number of carbon. Another, more revealing test of their intelligence might be to ask whether one should tell the truth, keep promises, or be just.

\section{Earthbound Ethics?}

Millennia before scientists, natural history produced moral agents, incrementally perhaps, but still appearing where there were none before. Ethics, like science, is distinctive to humans. There is no ethics in wild nature. To be ethical is to reflect on considered principles of right and wrong and to act accordingly, in the face of temptation. This is a possibility only human life, so that we expect and demand that persons behave morally and hold them so responsible.

Peter Singer's Ethics has a section "Common Themes in Primate Ethics," including a section on "Chimpanzee Justice," and he wants to "abandon the assumption that ethics is uniquely human" (Singer 1994, 6). But many of the behaviors examined (helping behavior; dominance structures) are more pre-ethical than ethical; he has little or no sense of holding chimpanzees morally culpable or praiseworthy.

Frans de Waal $(1996,209)$ finds precursors of morality, but concludes:

Even if animals other than ourselves act in ways tantamount to moral behavior, their behavior does not necessarily rest on deliberations of the kind we engage in. It is hard to believe that animals weigh their own interests against the rights of others, that they develop a vision of the greater good of society, or that they feel lifelong guilt about something they should not have done. Members of some species may reach tacit consensus about what kind of behavior to tolerate or inhibit in their midst, but without language the principles behind such decisions cannot be conceptualized, let alone debated.

Jerome Kagan $(1998,91)$ puts it this way: "What is biologically special about our species is a constant attention to what is good and beautiful and a dislike of all that is bad and ugly. These biologically prepared biases rend the human experience incommensurable with that of any other species." Completing a careful survey of behavior, Helmut Kummer $(1980,45)$ concludes, "It seems at present that morality has no specific functional equivalents among our animal relatives."

After her years of experience with chimpanzees, and although she finds pair bonding, grooming, and the pleasure of the company of others, Jane Goodall writes

I cannot conceive of chimpanzees developing emotions, one for the other, comparable in any way to the tenderness, the protectiveness, tolerance, and spiritual exhilaration that are the hallmarks of human love in its truest and deepest sense. Chimpanzees usually show a 
lack of consideration for each other's feelings which in some ways may represent the deepest part of the gulf between them and us (van Lawick-Goodall, 1971, 194).

In social animals, where reciprocal aid develops, as when monkeys give alarm calls, one animal can and does aid another, and the result (averaged over the population) is increased conservation of somatic and genetic value. (This is often called "reciprocal altruism," a misnomer, better to call it "reciprocity.") The result is maximal protection of values held in common by the animals involved. It would be a mistake in evolutionary strategy for one animal to lose where this did not bring high enough gains in kindred lives bound with it in community. Natural selection selects against such behavior.

Although we might not want to call it altruism, biologists are increasingly inclined to see that natural selection can promote not only competition but also cooperation. Martin Nowak claims, both on the basis of observation in the wild and of computer simulation, "Competition does not tell the whole story of biology. Something profound is missing. Creatures of every persuasion and level of complexity cooperate to live.... This is the bright side of biology" (Nowak 2011, xii-xiv). "Cooperation is the master architect of evolution," Nowak (2011, xviii) continues. "I have accumulated a wide range of evidence that competition can sometimes lead to cooperation," he writes (Nowak 2011, 14). "By cooperation, I mean that would-be competitors decide to aid each other instead" (Nowak 2011, xiv). Organisms are quite interrelated, living in communities, ecosystems, with myriad co-actions, co-operations, interdependencies.

Yes, but even if animals learn to cooperate as well as to compete, they are still seeking their self-interests, and this continues in human social animals. We next meet a claim often made by Darwinians, especially the evolutionary geneticists. Ethics is a survival tool; individual humans construct their ethics to keep their genes in the next generation. The explanation-so this claim runs-lies in a naturalized ethics, a Darwinized morality. That, of course, will be Earthbound, local, and likely individualized, or family, or tribal.

Michael Ruse, a philosopher, joins E. O. Wilson, a biologist:

Morality, or more strictly, our belief in morality, is merely an adaptation put in place to further our reproductive ends. Hence the basis of ethics does not lie in God's will... or any other part of the framework of the Universe. In an important sense, ethics... is an illusion fobbed off on us by our genes to get us to cooperate (Ruse and Wilson 1985, 51-52).

"Morality is a biological adaptation no less than are hands and feet and teeth," Ruse $(1994,15)$.

A Darwinized ethic will be Earthbound: "A conclusion of central importance to philosophy [is] that there can be no genuinely objective external ethical premises... No such extrasomatic guides exist." Ethics is "idiosyncratic" to the biology of a species (Ruse and Wilson 1986, 186, 173). Ruse and Wilson are especially anxious to conclude that there is nothing absolute or permanent, or extraterrestrial, about these ethical commandments; they fit our human biology and nothing more. 
Although a morality that conserves human genetic material is welcome enough, these claims bring deeper trouble. Evolution produces this fertility through a radical selfishness incompatible with ethics. George Williams $(1988,385)$ claims "Natural selection... can honestly be described as a process for maximizing shortsighted selfishness." Robert L. Trivers (1971, 35) claims that these are "models designed to take the altruism out of altruism." After these biological reinterpretations, we will not find altruism even on Earth. If so, we might not have sense enough to search for it among extraterrestrials in space.

Meanwhile at least genes have to be spread around; that is the only way they can be conserved. Fitness is not measured by an individual's own survival, long life, or welfare. Fitness is measured by what any individual can contribute to the next generation in its environment, fitness in the flow of life to pass life on. Survival of the fittest turns out to be survival of the better senders of whatever is of adaptive value in self into others in the next generation.

Genetic evolutionary natural history has generated "felt caring," when the sentient organism is united with or torn from its loves. The Earthen story is not merely of goings on, but of "going concerns." Animals hunt and howl, find shelter, seek out their habitats and mates, feed their young, flee from threats, grow hungry, thirsty, hot, tired, excited, sleepy. They suffer injury and lick their wounds. In physics and astronomy, we meet a causal puzzle, one of creation ex nihilo. Biology adds creation ex nisu, creation per laborem. To mechanical cause, there is added proactive care. There is death, but, with labor and regeneration, life ongoing. Selfish genes, once again, need to be cooperators in keeping life surviving in the midst of its perpetual perishing.

Listening to such biologists, extrapolating from the behavior of genes to the behavior of persons, we are puzzled by several facts: (1) Natural history produced persons with capacities with which they sometimes become scientists. (2) Some, but only some, of these scientists think ethics is an earth-bound illusion. (3) Natural history produced persons with capacities with which they sometimes (at least seem to) become altruists. (4) Ethicists claim that the human self achieves the novel possibility of acting as a moral agent. (5) The individual self can recognize and make its own concern questions about the worth of others outside its own local sector: contributing aid for the Ethiopians or for conservation of whales. The person can and ought defend values more comprehensive than those of self-love; a person can love the other as well as oneself. And such persons can flourish.

A possible line of resolution is to add culture to biology. In culture, one can gain enlarged interests and so an enlarged sense of identity. The first cultural unit is the nuclear family, where there is also genetic identity, kinship identity. But there is also tribal identity; here theories of "group selection" have been returning in ethics. In Unto Others, Elliott Sober and David Sloan Wilson find both selfinterest and at least in-group altruism: "Natural selection is unlikely to have given us purely egoistic motives," but rather a "motivational pluralism," enabling the tribe to survive, although they also insist that there is no "universal benevolence" (Sober and Wilson 1998, 9, 12, 324). So, within the community, we find the 
patriots in battle, the Rotarians building their public spirit, even the Christians loving both self and neighbors.

The cultural self, like the biological self, lives the life of myriads of interconnections, extending far beyond the family. One works for a business firm, serves on a town council, is a volunteer at the hospital, spends time in military service, makes a donation to the college of which he or she is an alumnus or alumna, supports a scientific research project, teaches a class of students with kindred interests, joins a conservation society, leaves a will with a bequest not only to children but to those institutions he or she wishes to see continue after death.

Almost everything that the self cares about has to be cared about in concert with others, in reciprocity. The cultural self comes to transcend, even to replace, in part, the biological self. But neither does this stay tribal or patriotic. What one wishes to survive is one's ideas, one's values, or, more accurately, those ideas and values into which one comes to be educated and in which one meaningfully and critically participates. That is true with the scientists; the scientists do not claim that by promoting their science they are simply attempting to leave more genes in the next generation. Nor are they simply defending the survival of their tribes, either racial or professional. So why should we think it true of the ethicists? In science, scientists believe that, although they operate within their biologies and their cultures, they sometimes know truths external to their interests, external to human affairs. Why deny that ethicists might do the same?

There are twin truths: Ethics does have to be "naturalized," to fit human biology, including human reproductive needs. One does not want an ethic of no Earthly use. A species-blind moral system would be inadequate. Ethics needs to be situated where the moral agents live, internal to the agents' conditions-physical, environmental, social, cultural. We can expect that human ethics will have evolved to suit human biology and to defend the sorts of values that persons can instantiate, enjoy, lose, and protect.

If resources are in short supply, there will need to be an ethic about stealing. If killing is possible, there will need to be an ethic about murder. If the moral agent is sexed, there will need to be an ethics of sexuality. If humans have lusts, there will need to be a command not to covet. Ethical principles will need to fit human sociology and psychology, as this is superimposed on our biology. Ethical principles will also need to fit human cultural institutions-such as contracts of marriage, or business dealings, or citizenship in states-many of which have little precedent in nature. Ethics will need to protect, both by defending and sharing, the multiple capacities that humans have for enjoying values. In this sense, information about behaving ethically where one does not reside is irrelevant.

Yet there is an exodus out of wild, spontaneous nature into the freedom of spirit in cultural life, superimposed on biological life. We never become free from nature, but we do become free within nature. Humans receive a biological legacy, but are elevated into a cultural process superimposed on the evolutionary one. Ethics is social and informs us how to make a way through both the social and the natural worlds. Perhaps humans do not need any ethics for larger realms than those in which they actually reside. But we do have sciences, as we were noticing, that in 
the course of discovering useful theories and laws for human affairs, also discover what is true for extraterrestrials. We are still wondering whether that might be also true in ethics.

\section{Inclusive Global Ethics}

Humans have expanded their territories all over the globe. They are also capable of asking how ought humans to live as they reside on this Earth we have so much occupied. Should each maximize his or her own self-interest, reciprocating as needs be to accomplish this? Should the rich grow richer, the privileged more privileged? Should each person maximize the number of his or her offspring? Each family? Each tribe? Each nation state? Should Homo sapiens as a species maximize the high intrinsic value of our kind? The most convincing answers urge a more global, more generous defense of value.

This better ethics, these cosmopolitans will argue, has to be universally shared; it generates concern for other humans near and far, relating to them with the moral values of justice, love, and respect. The commitment that one has to make transcends one's genetics and one's society. Any account of in-group altruism to achieve out-group competitive success is powerless to explain the universalism in the major world faiths. Humans can enter into an ethical contract with other humans, the principles of which are oblivious to the specific circumstances of time and place, genome or culture. Ethics—at least in ideal, if not in real-has "universal intent."

Immanuel Kant claimed that the fundamental moral precepts must be "universalizable," that is, what he called "categorical imperatives" applicable to all moral agents. He thought the Golden Rule was one such formulation of a universal morality (Kant [1785] 1964). The Golden Rule is indeed widespread in one form or another, especially in the classic world religions (Wattles 1996). Similarly with respect for life, or the greatest good for the greatest number. The Ten Commandments — at least the moral table - are for all humans, pan-culturally, pan-genetically. "Do not murder." "Do not steal." "Do not covet."

Ethics, according to John Rawls' influential account, takes up an "original position," based on judgments about what one would do if one did not know the particulars of one's birth and local circumstances (Rawls 1971). Ethics becomes globally inclusive - without denying that there may be differing duties to family, friends, community, business, heritage, ethnic or interest group, nation state, and humanity at large. Human values are widely distributed and shared, as witnessed, for example, in the Universal Declaration of Human Rights.

Such hope for an inclusive global ethics is not without its critics. To the claims of a Darwinized ethic, we must add a second main area of challenge, cultural relativism, also claiming that ethics is quite parochial. Ethics, these critics reply, is quite relative; do not the myriad behaviors of the myriad peoples amply illustrate that? Indeed, we have no one agreed-upon ethics even within the Western 
traditions, as differences between the utilitarians and the deontologists illustrates. Agreement on broad principles ("the greatest good for the greatest number") quickly splinters into fragmented actual decisions in practice (how far there should be public welfare, or whether to employ capital punishment). Agreement on the Golden Rule is more apparent than real; differing cultures and centuries put it into practice quite differently. Noble global principles are lofty but never functional. Not one person in ten million ever acts in specific circumstances after deliberating globally the greatest good for the greatest number. If one does so deliberate, in most of the contested decisions, a person seldom knows which of the immediate alternatives faced will result globally in the most good.

Some argue that ethics is set in the context of one's heritage (Maclntyre 1981). Ethics always goes into some larger interpretive framework, some worldview. In reaching ethical conclusions, differing peoples give different weights to the importance of individuality versus family versus community, or rights versus duties versus virtues, or justice versus fairness versus benevolence, or freedom versus determinism, or forgiveness versus reparations versus retaliation, or past versus present versus future generations, or reason versus emotion, or censure versus praise, grace versus merit. Ethics is continually evolving, as with decisions about brain death, or homosexuality; we next face decisions about genetically modifying ourselves. Only the historically naive will claim that humans have reached any established cultural ethic, much less some transglobal ethic.

Nevertheless, ethical systems do reach around the globe. Differing contexts and evolving traditions do not preclude some commonality in ethics. The major world faiths have escaped parochial tribalism, not only in ideal but also in the real proportionately to their success. It seems impossible to explain their ecumenical and inclusive global missions on the basis of either genetics or local traditions. Somehow, somewhere these missionary ethicists reached insight into a better standard of what is right. One's culture is subject to on-going critical re-evaluation.

These religions criss-cross races, nations, and centuries; they operate in diverse times and cultures, and involve some logic of the mind that is tracking what is transgenetically and transculturally right or of value, no matter whether one has this or that set of genes or was born in this or that culture. Genetic success in each local community is necessary but not sufficient to explain this universalism. Nor are these widespread and persistent concerns so easy to "deconstruct" as nothing but local "social constructions." It is more plausible to conclude that such religions have been discovering what is trans-tribally, trans-culturally valuable.

In interhuman ethics there is already a striking novelty, unprecedented in prior natural history. In environmental ethics, rather than using mind and morals as survival tools for defending the human form of life, or my tribal heritage, mind generates an intelligible view of the whole and defends the varieties of life in all their forms, not just other peoples but nonhumans too. Humans transcend their own concerns. Humans can get "let in on" more value than any other kind of life. The novelty is class altruism emerging to coexist with class self-interest, sentiments directed not simply at one's own species but at other species fitted into biological communities. Humans can and ought to think from an ecological 
analogue of the original position, a global position that sees Earth objectively as an evolutionary ecosystem. Interhuman ethics has spent several millennia waking up to human dignity. Environmental ethics invites awakening to the greater story of which humans are a consummate part.

So both in interhuman ethics and in interspecific ethics, humans do seem to be able to reach more inclusive and comprehensive standards. Humans can aspire to global dimensions in their ethics. But perhaps ethics is still Earthbound?

\section{Universal Ethics}

We know only one ethical species and it is difficult to universalize from only one known case. Perhaps humans do not need any ethics for larger realms than those in which they actually reside; a global ethic is aspiration enough. Even if we contact extraterrestrial intelligence, we are quite unlikely to have any direct, interactive dealings with civilizations many light years away, certainly not moral responsibilities resulting from our actions affecting them for better or worse. Nor they with us.

Still it may be worth inquiring whether to expect that extraterrestrial intelligence will be moral. One pointer in that direction will involve conclusions about whether and how far we humans already know what such intelligences will know. The human mind sometimes seems to be able to reach truths about realms that it does not inhabit, extrapolating and reasoning from the realms that it does (as we were claiming with scientists). So we can ask whether the human mind can reach ethical principles that may transcend our somatic embodiment, that are "objective" to our humanity, and therefore likely to be shared with extraterrestrials.

In the ultra-sophisticated circles of postmodern epistemology, if describing universal nature as if it objectively exists is an illusion, finding universal moral values is still more illusion, illusion-on-stilts. That would require us further still to do what we cannot do, get out of our skins, get a "view from nowhere," get (God forbid!) the "God's eye view." "Absolute" is a forbidding word; epistemologists will be reticent about using it. "Universal" is not so "absolute"; perhaps we can claim that some of our moral insights, if perhaps not true in all possible worlds, are at least true elsewhere in our universe.

Extrapolating from our progress toward an inclusive global ethics, some insights in our human moral systems may be transhuman. Keep promises. Tell the truth. Do not steal. Respect property. Love your enemies; do good to those who hate you. Such commandments may be imperatives on other planets where alien species of moral agents inhabit inertial reference frames that have no contact with ours. Wherever there are moral agents living in a culture that has been elevated above natural selection, one can hope that there is love, justice, and freedom, although we cannot specify what content these activities will take in their forms of life.

In these worries about how comprehensive humans can be in their ethical systems, the focus on altruism is central, because that is particularly hard to explain. But perhaps we should recall that neither in deontological ethics nor in 
utilitarianism, the two main Western traditions, is altruism the sole ethical principle. The moral agent does what is just, giving to each his or her due; and whether this due is to self or other is secondary. The agent does the greatest good for the greatest number, which might mean benefits to self and/or to other, depending upon options available. The Golden Rule urges one to love neighbor as one does oneself, but this is not other love instead of self-love. "Do to others as you would have them do to you" seeks parallels in the self doing for others with others doing for the self, suggesting reciprocity as much as antithesis between self and other. Doing the right, the good is a matter of optimizing values, which often indeed means sharing them, but this is never simply a question of benefiting others instead of oneself. Ethics is about optimizing and distributing moral and other values. This is a more comprehensive question than whether the self is preferred over others or vice versa.

\section{G. K. Chesterton states our conclusion forcefully:}

Reason and justice grip the remotest and the loneliest star. Look at those stars. Don't they look as if they were single diamonds and sapphires? Well, you can imagine any mad botany or geology you please. Think of forests of adamant with leaves of brilliants. Think the moon is a blue moon, a single elephantine sapphire. But don't fancy that all that frantic astronomy would make the smallest difference to the reason and justice of conduct. On plains of opal, under cliffs cut out of pearl, you would still find a notice-board, "Thou shalt not steal" (Chesterton [1911] 1976, 23).

It certainly does not follow that nothing generally true can appear in human morality because it emerges while humans are in residence on Earth. There is nothing particularly Earthbound about: "Do to others as you would have them do to you." That could be true whether or not the moral agents are Homo sapiens. If there are moral agents with values at stake in other worlds, this could be universal truth.

If visitors from outer space were to arrive and wish to set up a space station that required capturing humans as slaves to build their station, would we not urge "universal human rights" upon these extraterrestrials. If they proceeded, would we not censure them? If they could not understand our urging, we would think their intelligence inferior to ours. If they tried to justify their action by claiming their advanced intelligence, we would judge them morally retarded. If they also set up their space station in ways that required destroying a rich tropical forest ecosystem, filled with endangered species, would we not urge this non-Earthen species to respect Earth's biodiversity? If they did not, again, we would censure them and think them morally inferior.

The ethics that humans have reached, although certainly one appropriate to our Earthen residence, discovers values that are objective enough to urge on moral agents from whatever extraterrestrial origin. There would be something censurable about moral agents anywhere, anytime who lied, cheated, stole, hated, or were unjust. Or caused unwarranted pain in animals. Or destroyed endangered species without adequate justification. One can plausibly venture the claim that if there are moral agents anywhere, anytime, they have not matured until they have reached the capacity for altruism - indeed, if we listen to sensitive religious ethicists, until they have acquired the capacity for suffering love. 
The surprising thing is that we humans have enough wit to do this, whether by revelation and prophecy, or by creative human inspirations and breakthroughs that rise to new levels of respect, caring, and compassion. As ethics matures, we are left wondering if it does not move beyond both nature and culture, glimpsing universals come to expression point on Earth. If there is life elsewhere, we have this logical warrant for expecting that even super-intellects will be moral agents who have reached parallel convictions.

\section{References}

Chesterton, G. K. [1911] 1976. The Innocence of Father Brown. New York: Garland Publishing, de Waal, Frans. 1996. Good Natured: The Origins of Right and Wrong in Humans and Other Animals. Cambridge, MA: Harvard University Press.

Kagan, Jerome. 1998. Three Seductive Ideas. Cambridge: Harvard University Press.

Kant, Immanuel. [1785] 1964. Groundwork of the Metaphysic of Morals. New York: Harper and Row.

Kummer, Helmut. 1980. "Analogs of Morality among Nonhuman Primates." In Morality as a Biological Phenomenon, edited by Gunter Stent, 31-47. Berkeley: University of California Press.

Maclntyre, Alasdair C. 1981. After Virtue: A Study in Moral Theory. Notre Dame, IN: University of Notre Dame Press.

Nowak, Martin A., with Roger Highfield. 2011. Supercooperators: Altruism, Evolution, and Why We Need Each Other to Succeed. New York: Free Press.

Polanyi, Michael. 1962. Personal Knowledge: Towards a Post-Critical Philosophy. New York: Harper and Row.

Rawls, John. 1971. A Theory of Justice. Cambridge, MA: Harvard University Press.

Ruse, Michael. 1994. "Evolutionary Theory and Christian Ethics: Are They in Harmony?" Zygon: Journal of Religion and Science 29:5-35.

Ruse, Michael, and Edward O. Wilson. 1985. "The Evolution of Ethics." New Scientist 108 (17 October):50-52.

Ruse, Michael, and Edward O. Wilson. 1986. "Moral Philosophy as Applied Science." Philosophy 61:173-192.

Singer, Peter. 1994. Ethics. New York: Oxford University Press.

Sober, Elliott, and David Sloan Wilson. 1998. Unto Others: The Evolution and Psychology of Unselfish Behavior. Cambridge, MA: Harvard University Press.

Trivers, Robert L. 1971. "The Evolution of Reciprocal Altruism." The Quarterly Review of Biology 46:35-57.

van Lawick-Goodall, Jane, 1971. In the Shadow of Man. Boston: Houghton Mifflin.

Wattles, Jeffrey. 1996. The Golden Rule. New York: Oxford University Press.

Williams, George C. 1988. "Huxley's Evolution and Ethics in Sociobiological Perspective." Zygon: Journal of Religion and Science 23:383-407. 